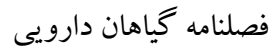

اثر عصاره اتانولى بيه انار بر قلب ايزوله رت متعاقب ايسكمى و برفوزيون مجدد

كاوه رحيمى'، حميدرضا كازرانى

1- دكترى فيزيولوزى، مركز تحقيقات علوم سلولى و مولكولى، يزوهشكده توسعه سلامت، دانشكاه علوم

يزشكى كردستان، سنندج، ايران

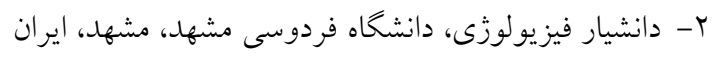

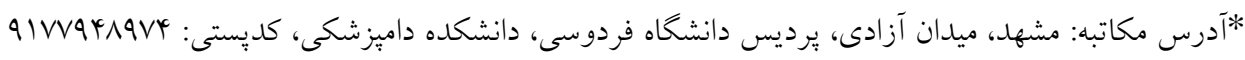

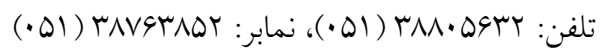

يست الكترونيك: kazerani@um.ac.ir

doi: $10.29252 / \mathrm{jmp} .4 .72 .241$

تاريخ تصويب:

تاريخ دريافت: 9V/O/I0

جكيده

مقدمه: بيمارى ايسكميك قلب مهم ترين عامل مرگ و مير در جهان به شمار مىرود.

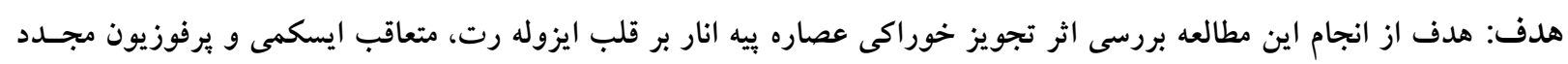
ميو كارد بود.

روش بررسى: در اين مطالعه قلب رتها تحت بيهوشى عميق خارج شد و توسط دستخاه لانگن دورف مورد مطالعه قرار كرفـت.

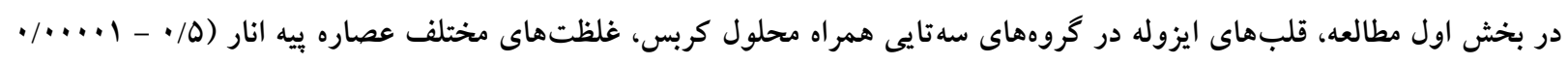

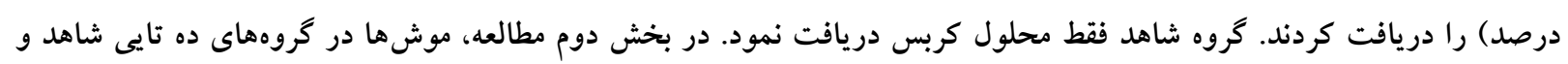

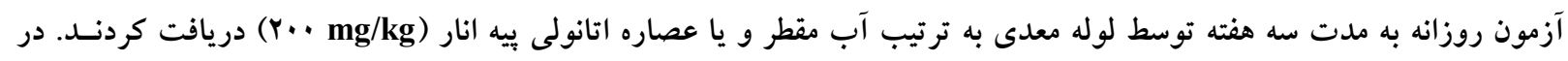

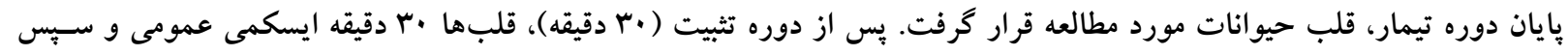

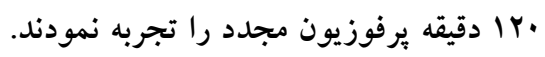

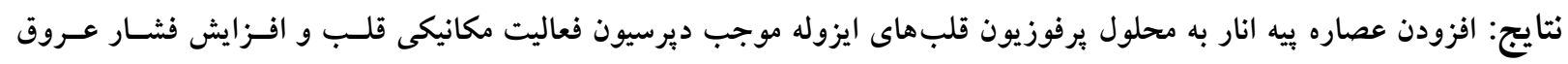

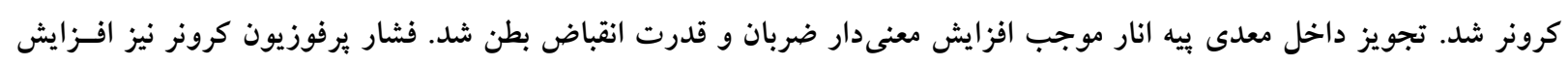

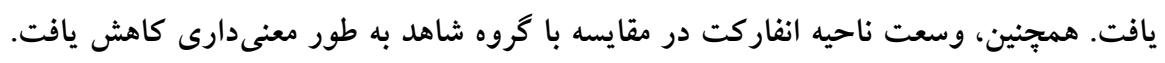

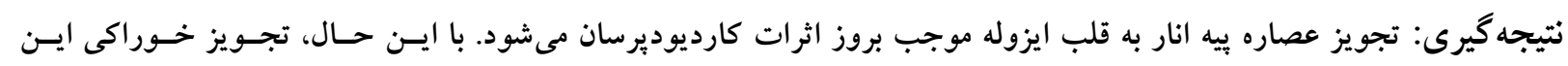

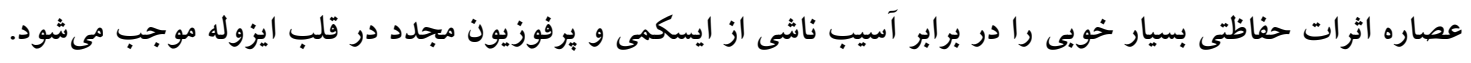

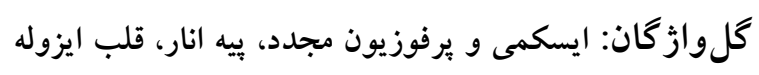


يّالاكتها، مهار يروليفراسيون و آنزيوزنز نسبت داده مىشود

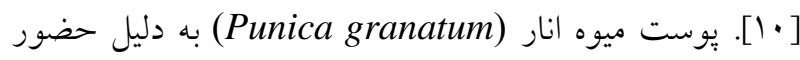

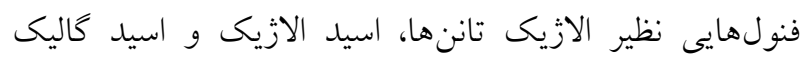

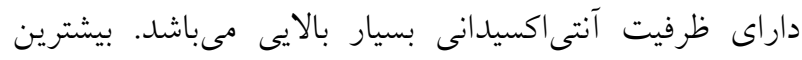

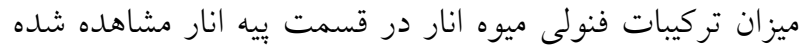

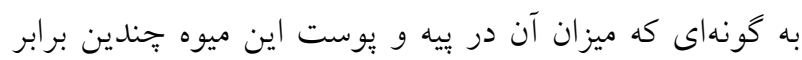

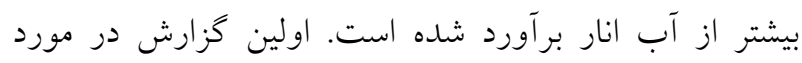

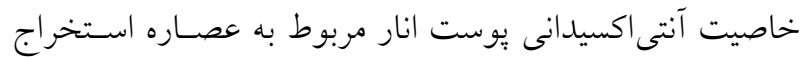

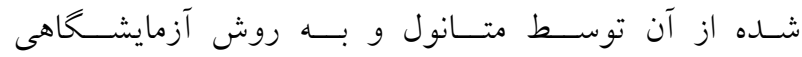

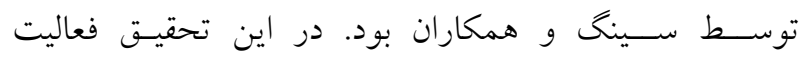

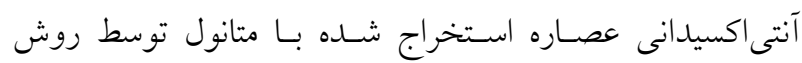

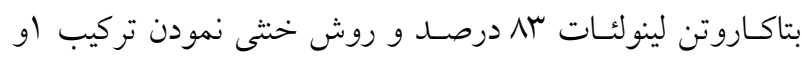

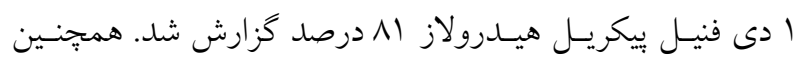

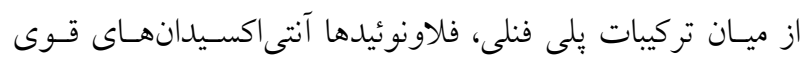

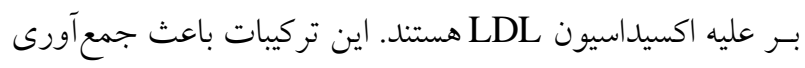
و از بين بردن راديكالهـاى هيدروكسيل، يراكسيد و و آنيون

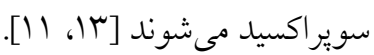

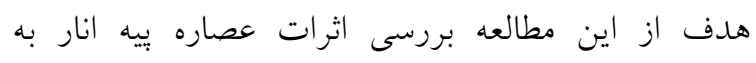

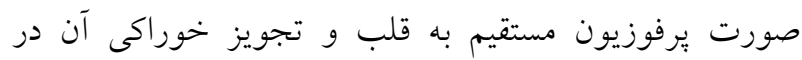

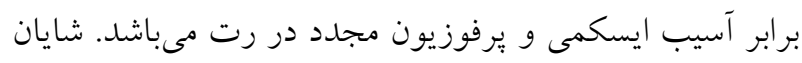

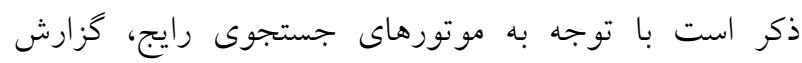
مشابهى در اين رابطه قابل دسترسى نبود.

\section{مواد و روش ها عصارهگيرى بيه انار}

ميوه تازه انار رقم شيشه كِّ فردوس انَّ از ناحيه خراسان

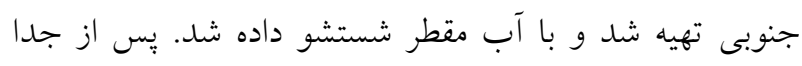
كردن يوست ييه انار (بخشهاى سفيد داخل يوسته ميوه انار)

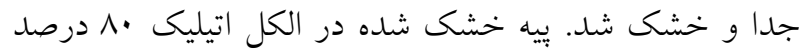
به ملت Y Y ساعت در دماى TV درجه سانتى گراد و در داخل

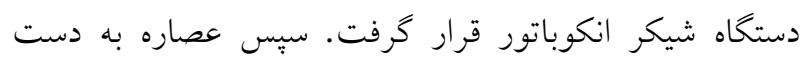

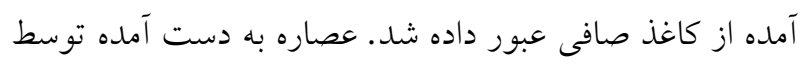

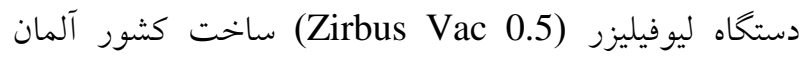

مقلمهه

بيمارى ايسكميك قلب يكى از دلايل اصلى مرى و مير در

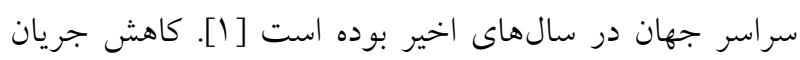

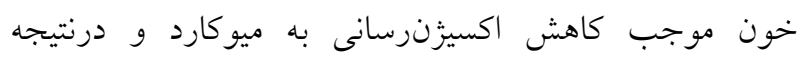

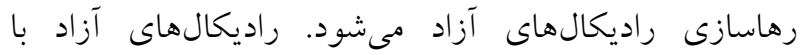

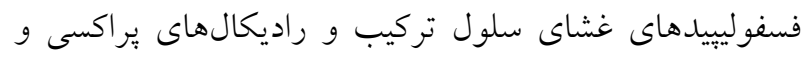

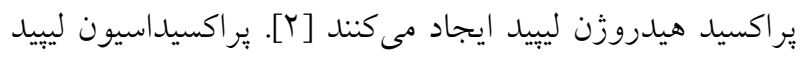
باعث توليد تركيب سيتوتوكسيك مالون دى آلدهيد مى مئدوند

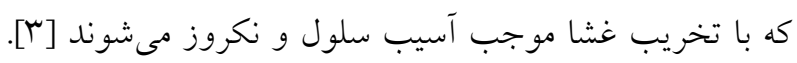
كزارش شده است كه راديكالهاى آزاد اكسيزن (ROS)

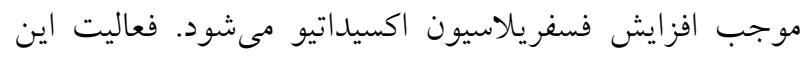

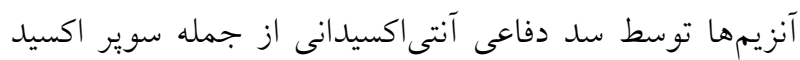

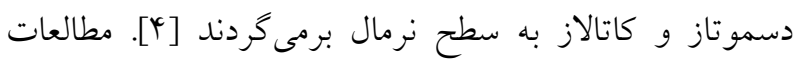

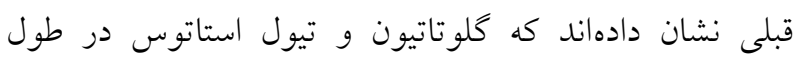

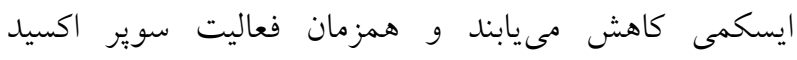

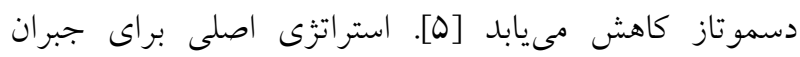

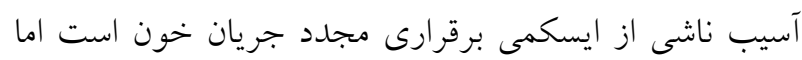

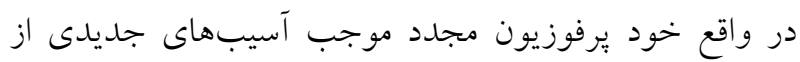

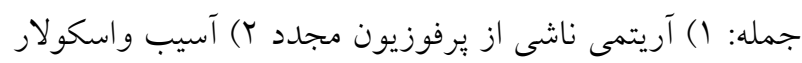

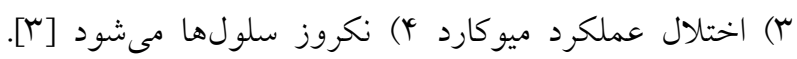

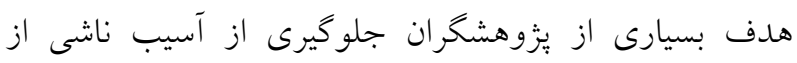

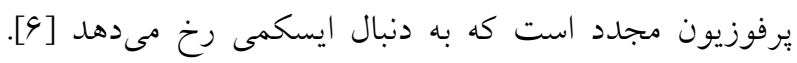

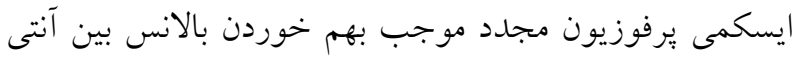

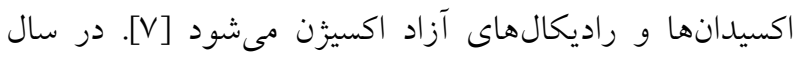

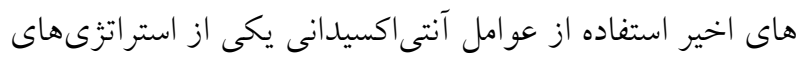

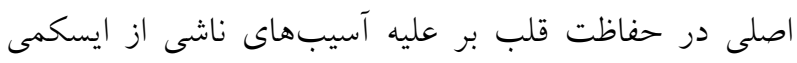

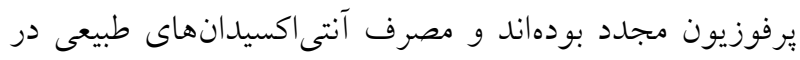

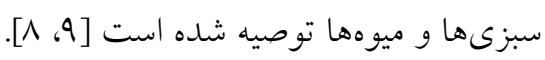

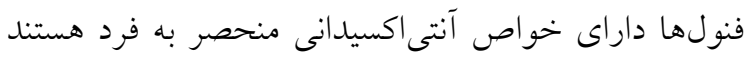

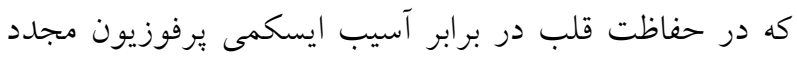

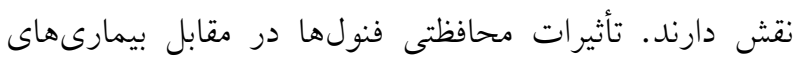

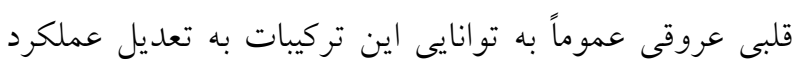

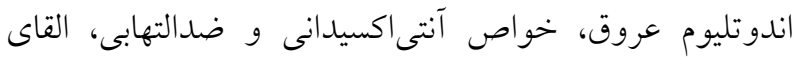

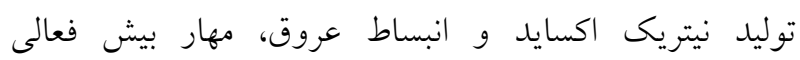


رحيمى و كازرانى

نيست و دوز فوق بر اساس دوزهاى به كار رفته در ساير

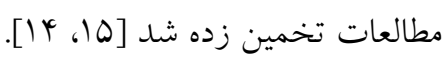

$$
\text { يرفوزيون قلب ايزوله }
$$

رتها توسط تزريق داخل صفاقى داروى بيتوباربيتال سديم

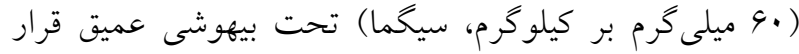

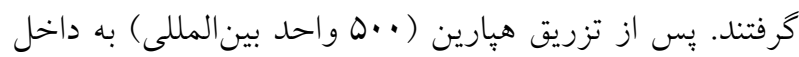
وريد يشتى قضيب، قفسه سينه شكافته و قلب حيوان خارج شد. قلبهاى مجزا در محلول كربس صفر درجه قرار گرفته و بلافاصله ضمن اتصال به دستخاه لانخين دورف، توسط محلول كربس (بر حسب ميلى مول در ليتر: NaCl:

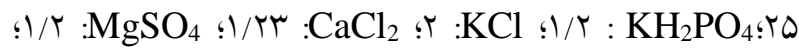

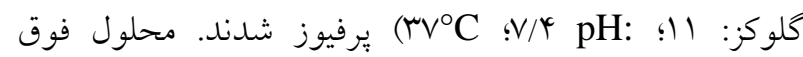
حداقل ·r دقيقه قبل از شروع و طى دوره آزمايش توسط كازهاى اكسيزن و دى اكسيد كربن (به ترتيب با نسبتهاى هون و ه درصد حجم) حبابدهى مىشد [19]. طى مدت آزمايش، ثبت ECG توسط دو الكترود كه به كوشك راست و نوى قلب متصل بودند توسط دستخاه

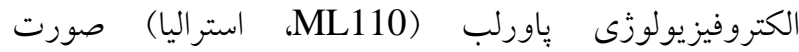
مى گرفت. فشار برفوزيون كرونر از طريق يك سه راهئ راهى كه قبل از كانول آئورت قرار كرفته بود توسط يك ترانس ديوسر فشار (MLT844) طريق يك بالون كوجى از جنس لاتكس كه به يك ترانس ديوسر فشار ديخر متصل بود ثبت مىشد. ضربان قلب از طريق ECG نوسانات فشار داخل بطنى و هم:جنين بر اساس سيكل

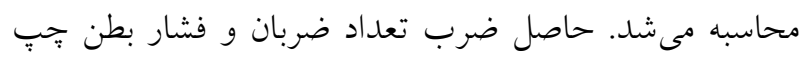
به عنوان شاخصى از (rate pressure product: RPP) فعP = HR × LVDP فعاليت مكانيكى قلب توسط فرمول محاسبه شد. درصد RPP بر اساس ميزان آن در ابتداى آزمايش جهت مقايسه در نظر كرفته شد. در پيايان دوره يرفوزيون مجدد، قلبها توزين شده و

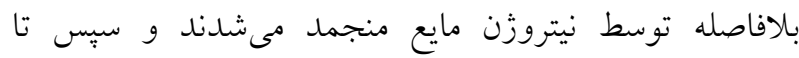

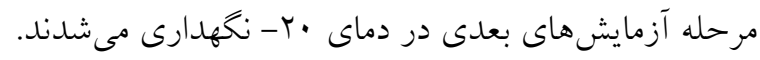

خشك شد و تا زمان انجام آزمايش به دور از رطوبت و در دماى •r- درجه نخههارى شد.

حيوانات مورد آزمايش اين مطالعه بر روى رتهاى نر نزاد ويستار با ميانخين

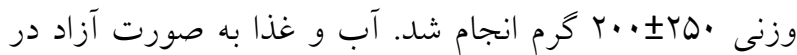
اختيار حيوانات قرار گرفت و حيوانات تا زمان آزمايش در

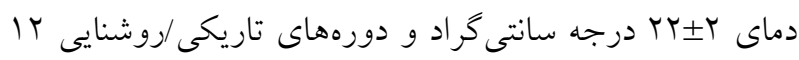

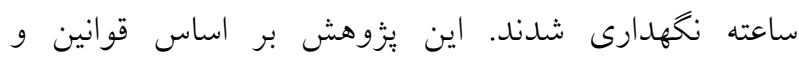
دستورالعمل كميته اخلاق حيوانات دانشخاه فردوسى مشهل يتروسي صورت يذّيرفت.

\section{كروههاى آزمايشى}

بخش اول مطالعه جهت بررسى مقدماتى امكان تجويز مستقيم عصاره بيه انار همراه با محلول كربس به قلبهاى

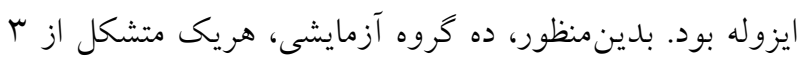

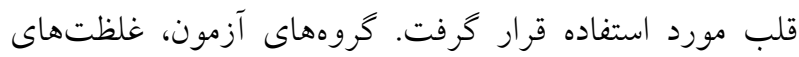
مختلف عصاره اتانولى بيه انار (ه/ • درصد تا |+... • • درصد) را به مدت ·r دقيقه يس از دوره تثبيت همراه با محلول كربس دريافت مى كردند. گروه شاهد عصاره دريافت نكرد. در مرحله دوم يزوهش، رتها به طور تصادفى در دو گروه

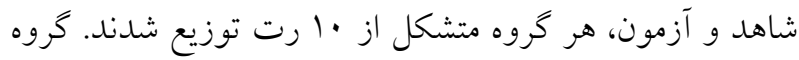

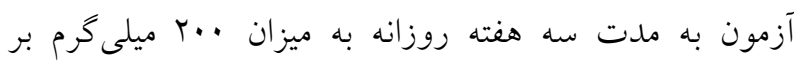
كيلوگرم عصاره اتانولى بيه انار توسط لوله معدى خورانده شد. كروه شاهد حجم مشابهى از دارونما (آب مقطر ) دريافت نمود. پس از اتمام دوره تيمار، قلب حيوانات مورد مطالعه با روشى مشابه مرحله اول تحت بيهوشى عميق از قفسه سينه خارج شد

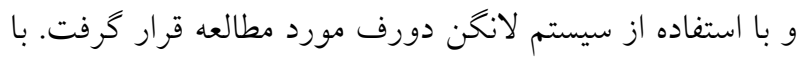
اينحال در اين مرحله يس از تثبيت قلب، با قطع جريان كربس

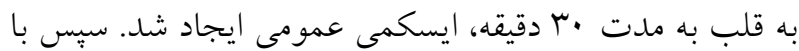
برقرارى مجدد جريان كربس به مدت • إ دقيقه، قلبهاى ايزوله يرفوزيون مجدد را تجربه نمودند. شايان ذكر است هيج گزارشى در رابطه با اثرات قلبى عصاره بيه انار در دسترس 
كرافيد يريزم (GraphPad Software, USA) صورت

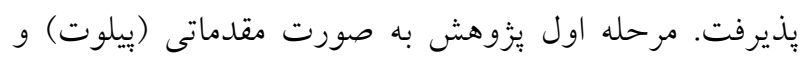

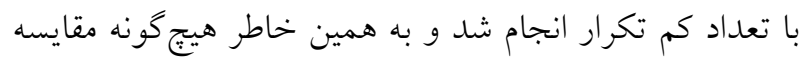

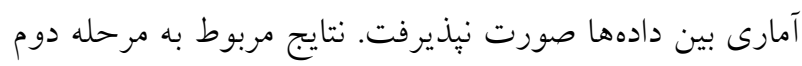

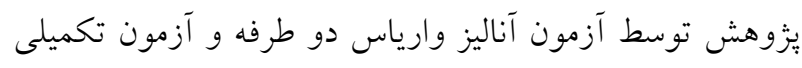

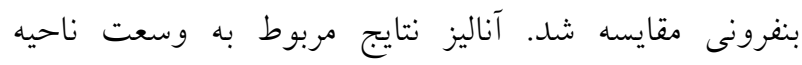

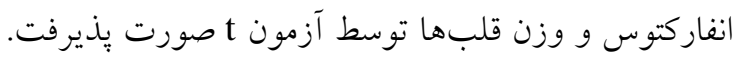

نتايج

در مرحله اول اين يزوهش، اثر مستقيم غلظتهاى مختلف

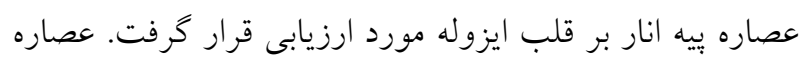

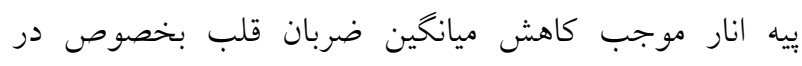
غلظتهاى بالا شد (نمودار شماره ()).

$$
\text { اندازهيرى وسعت ناحيه انفاركتوس }
$$

جهت اندازهيرى وسعت ناحيه انفاركتوس، قلبها ونا با استفاده

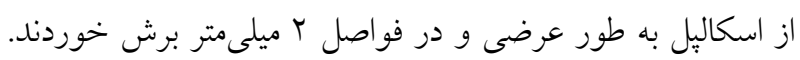
قطعات به داخل يترى ديش حاوى محلول يكى درصد ترى فنيل

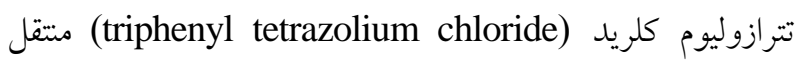
شده و به مدت • ا دقيقه در دماى rV درجه سانتى كراد انكوبه

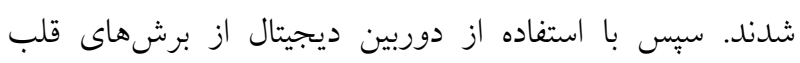

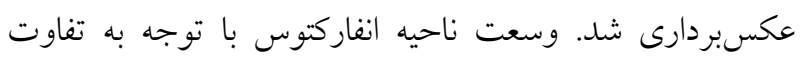

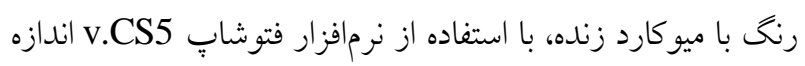

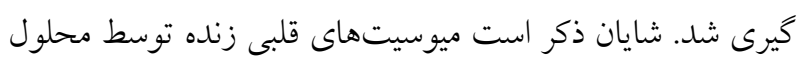

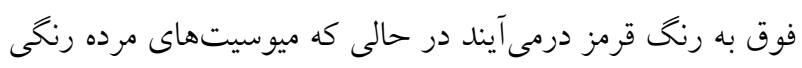
متمايل به سفيد خواهند داشت. آناليز آمارى ارزيابى آمارى و رسم نمودارها توسط نرمافزار آمارى

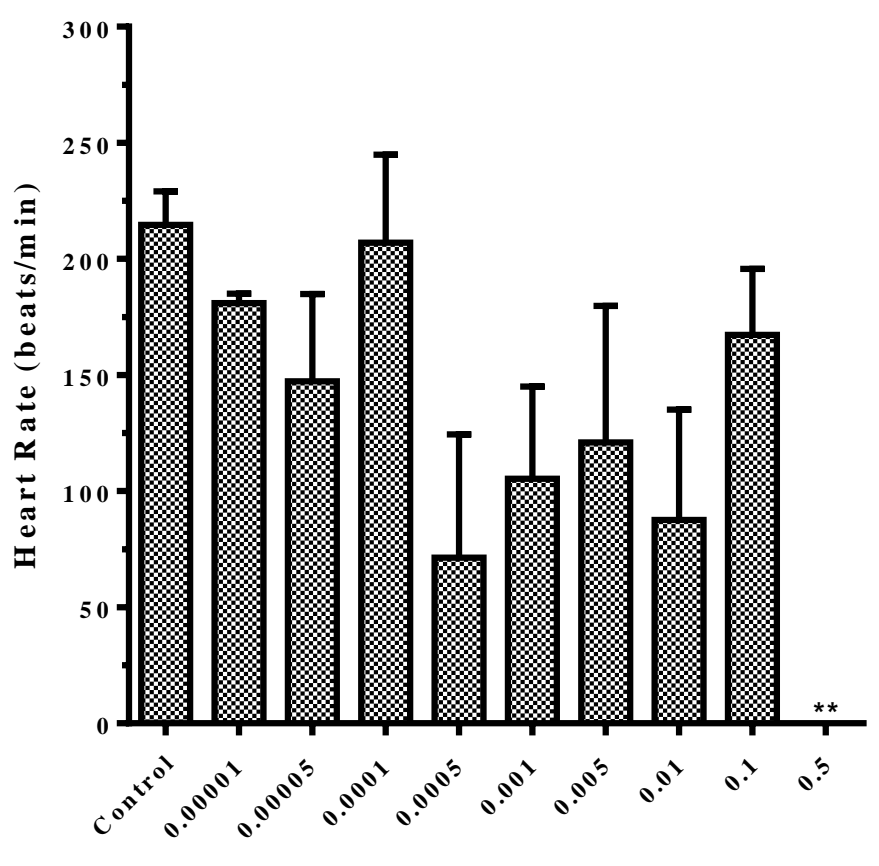

Mesocarp Ethanol Extract \%

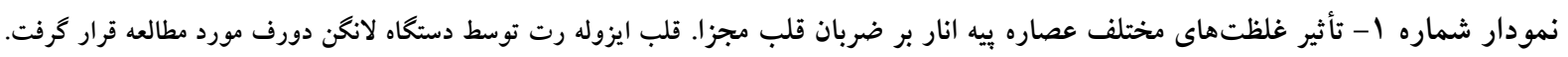

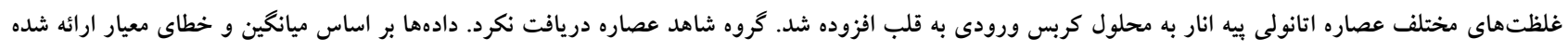


رحيمى و كازرانى

متعاقب قطع محلول كربس، طى دوره برفوزيون مجلدد ميانخين

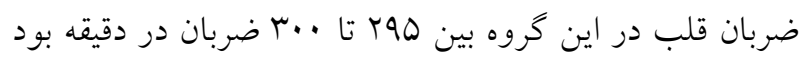

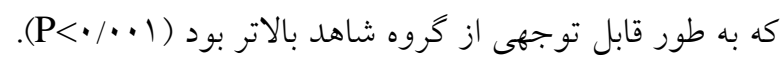

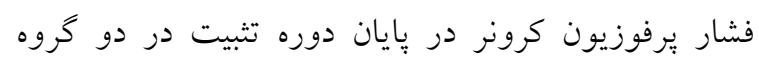

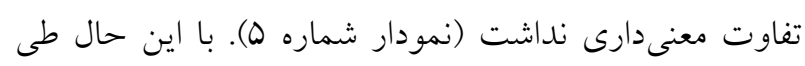

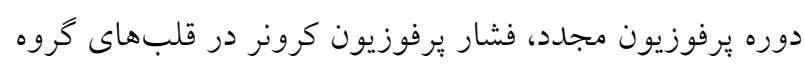

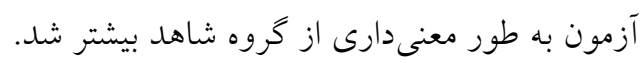

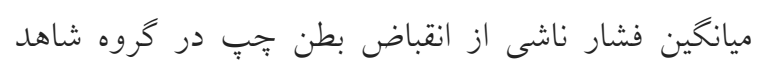

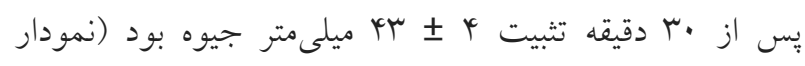

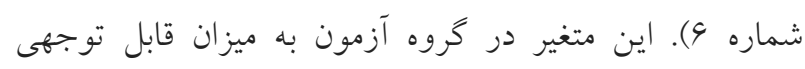

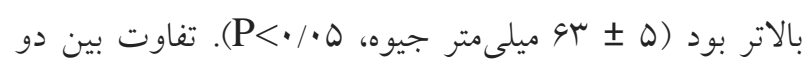

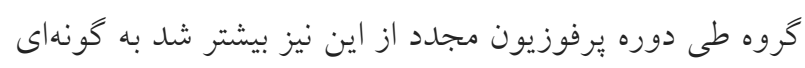

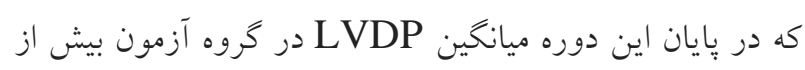

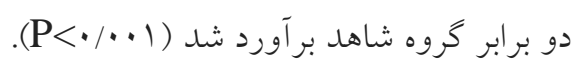

كصاره يِيه انار هميجنين موجب افزايش فشار يرفوزيون

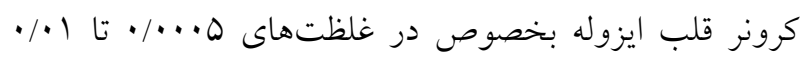
درصد شد (نمودار شماره Y).

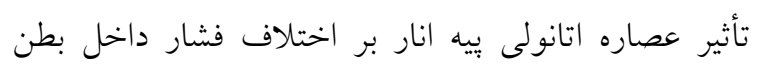

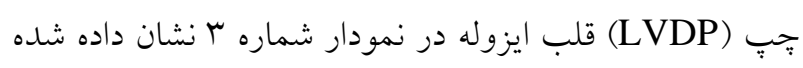

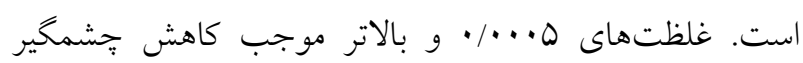
شدند LVP در بخش دوم اين مطالعه، ميانخين ضربان قلب يس از دوره

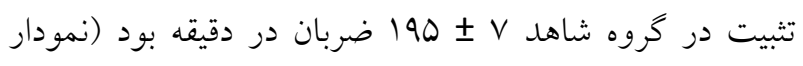

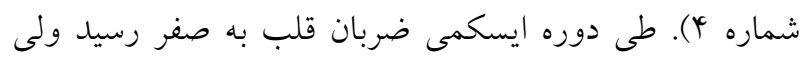

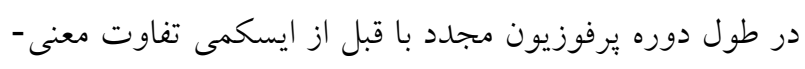

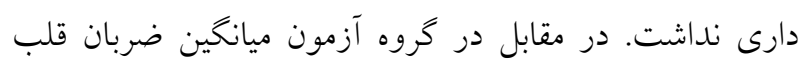

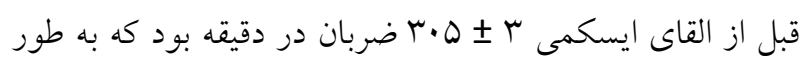
معنى

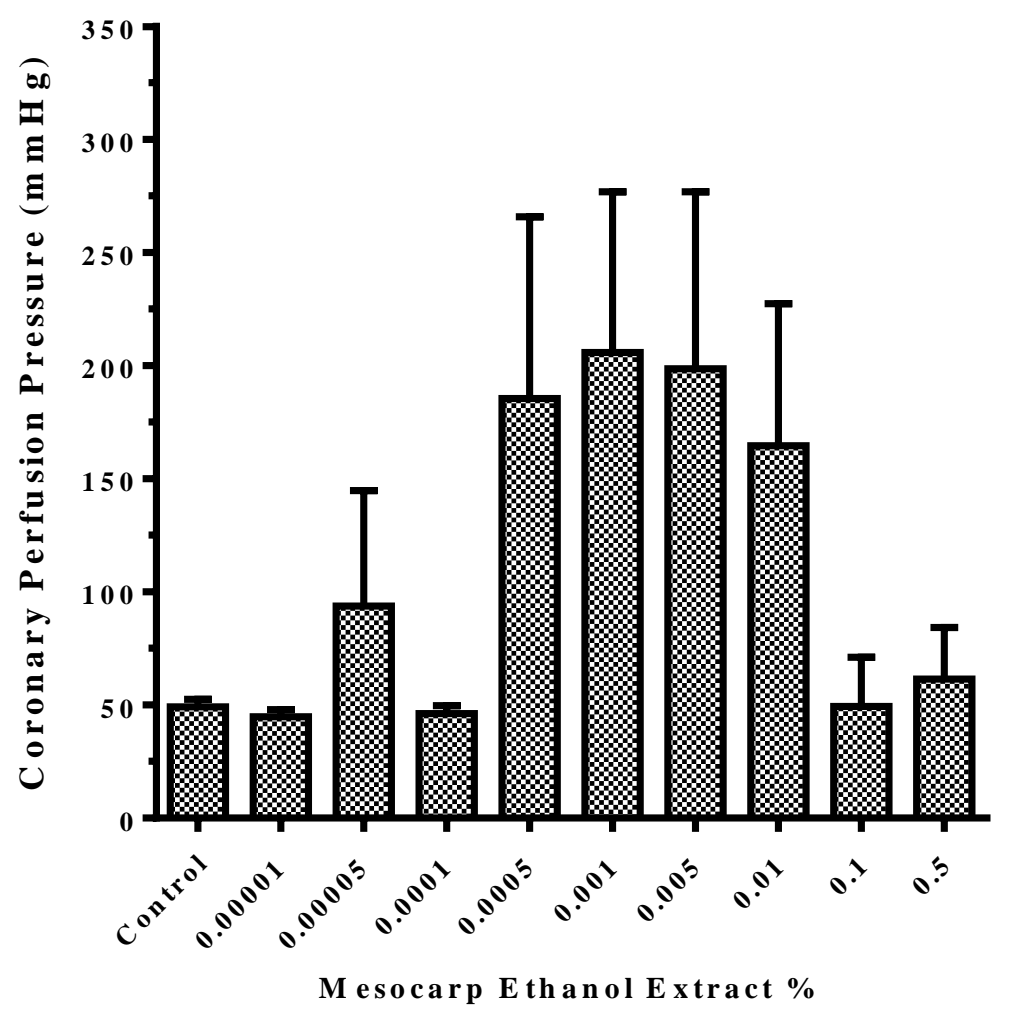

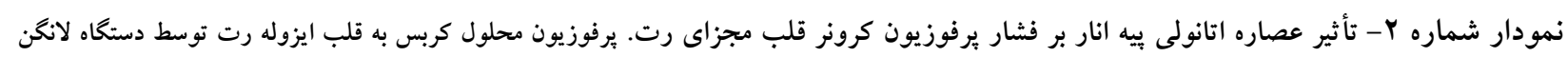

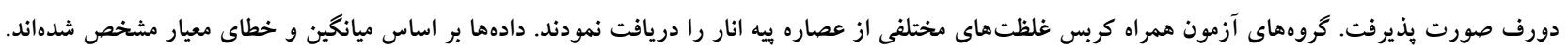




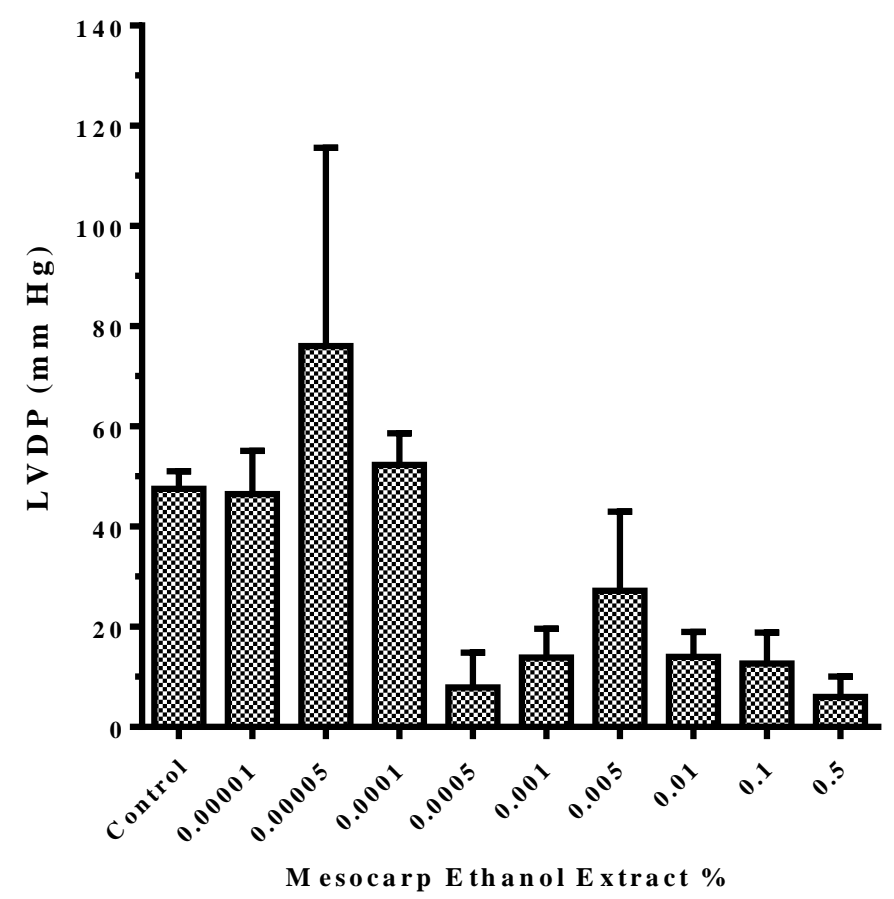

نمودار شماره ب- تأثير عصاره اتانولى بر فعاليت انقباضى بطن جٍٍ (LVDP) قلب مجزاى رت. برفوزيون قلب مجزاى رت توسط دستخاه لانگن دورف انجام

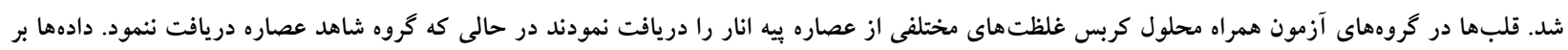
اساس ميانخين و خطاى معيار نشان داده شدهاند.

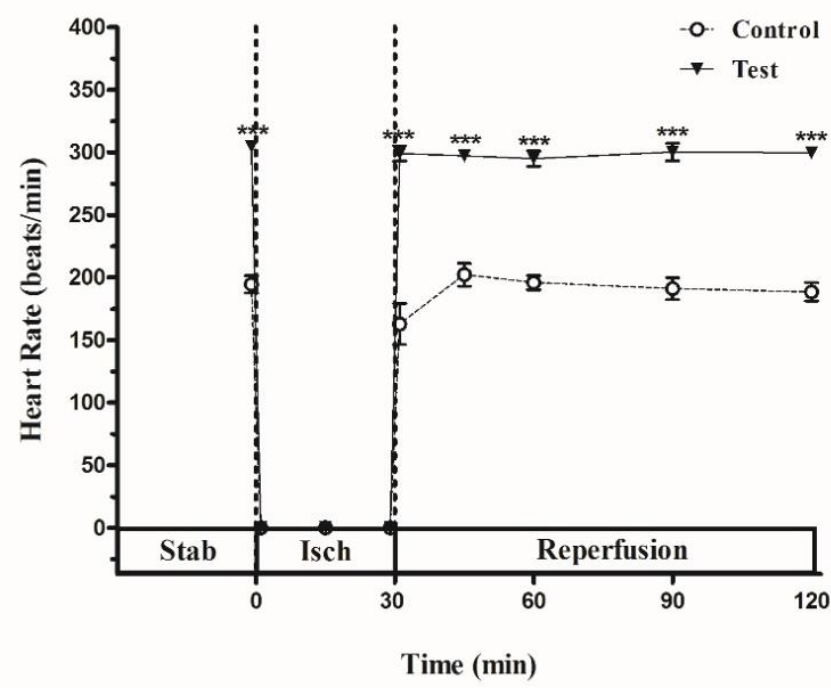

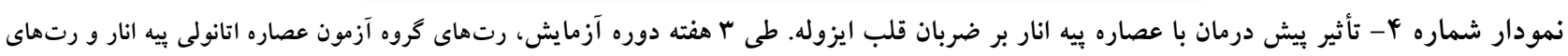

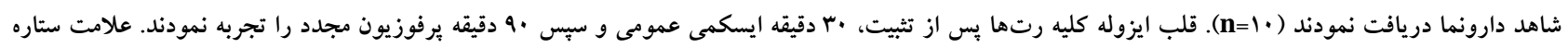

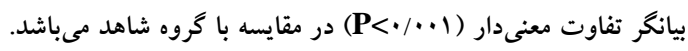


رحيمى و كازرانى

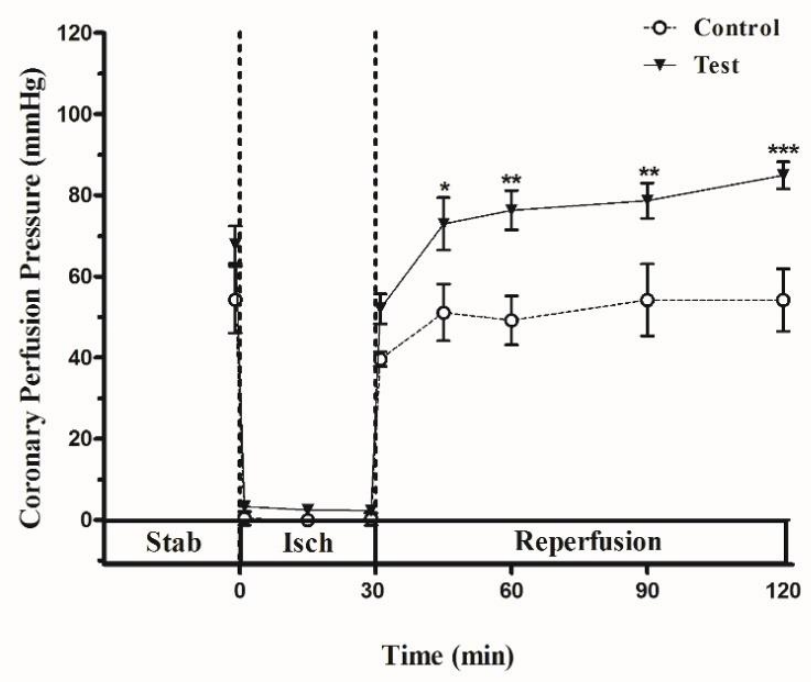

نمودار شماره ه- تأثير عصاره بيه انار بر فشار برفوزيون قلب ايزوله. عصاره بيه انار و دارونما به مدت r هفته به ترتيب به رتهاى آزمون و شاهد كاواز شد.

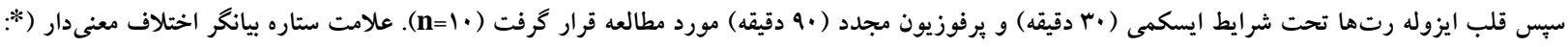

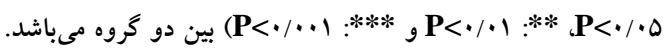

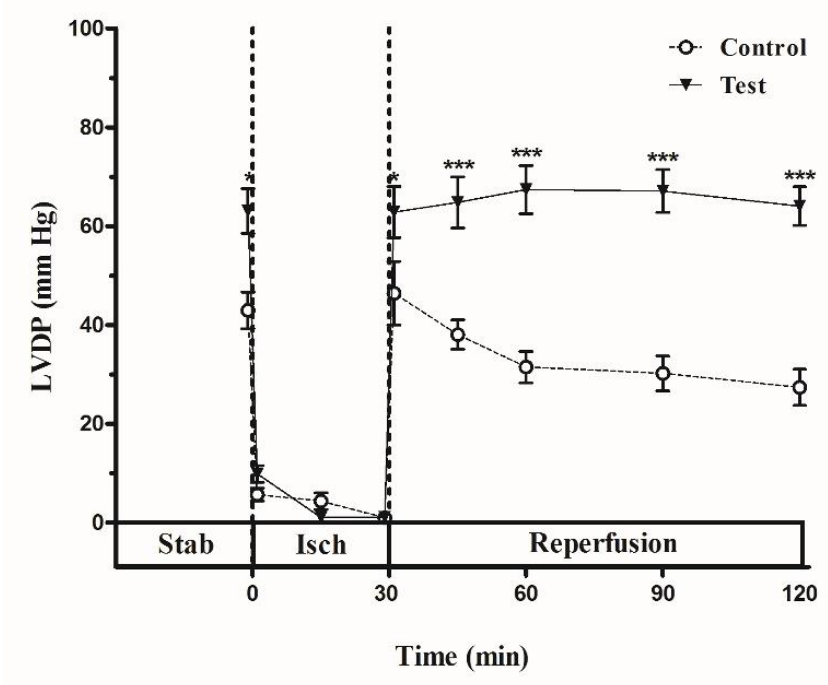

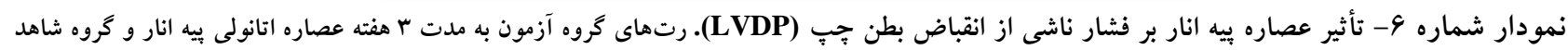

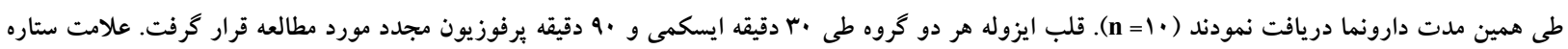

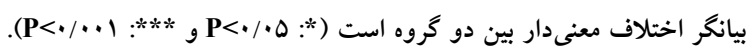

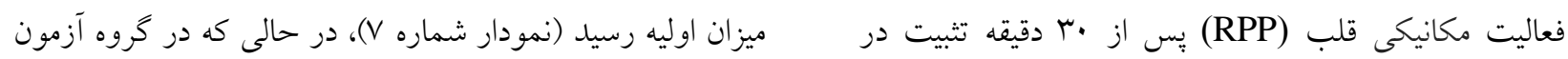

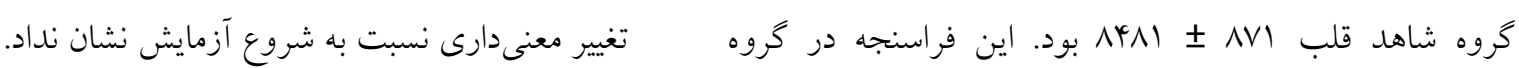

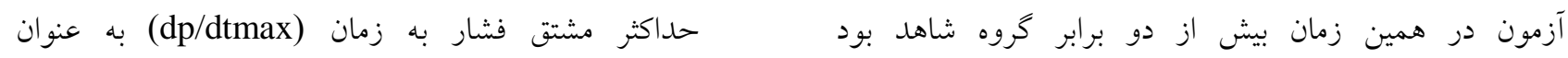
(P.4

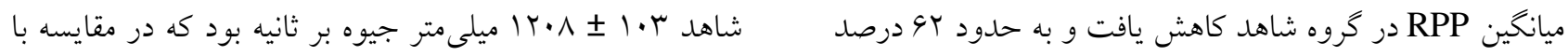




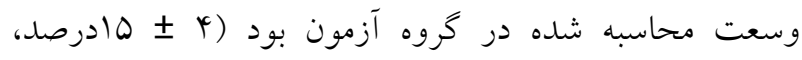

. $(\mathrm{P}<\cdot / \cdots)$

ميانخين وزن قلب در گروه شاهد 9/. گرم و در گروه

عصاره اتانولى بيه انار ب/ آ گرم بود (نمودار شماره • (1). تفاوت

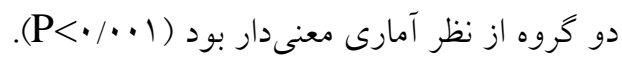

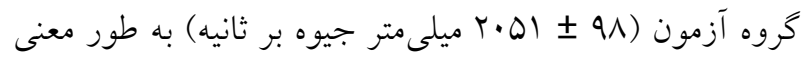

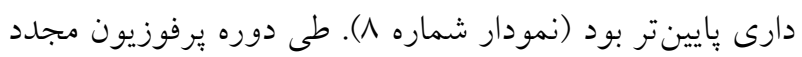

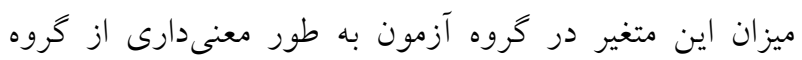

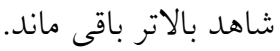

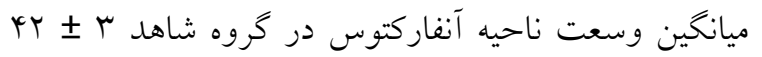

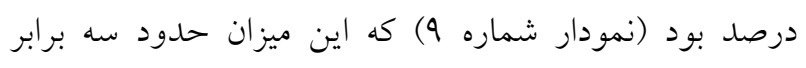

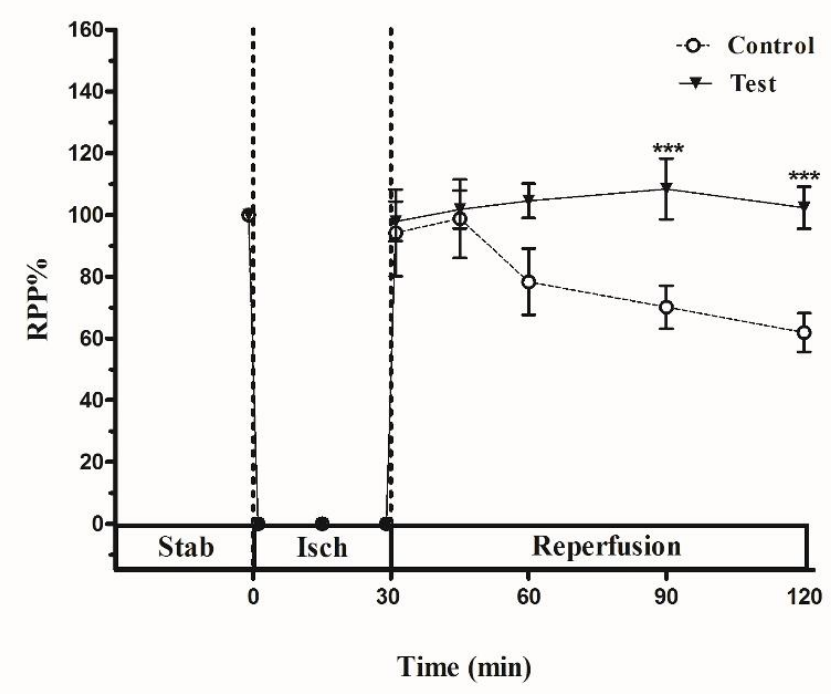

نمودار شماره V- تأثير عصاره ييه انار بر درصد فعاليت مكانيكى قلب (RPP\%). رتها در گروههاى شاهد و آزمون به مدت r هفته به ترتيب دارونما و يا

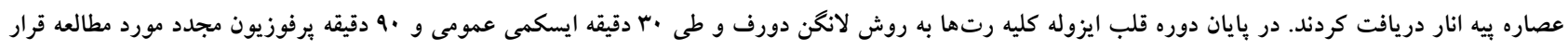

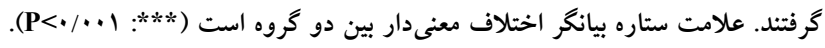

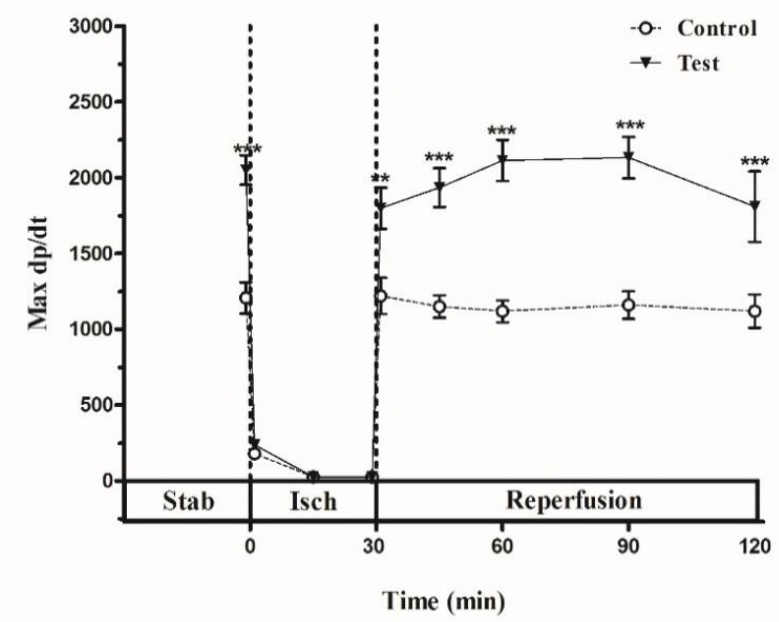

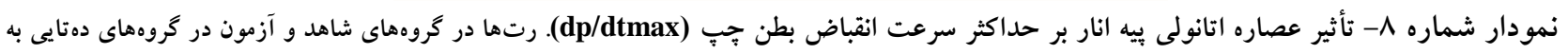

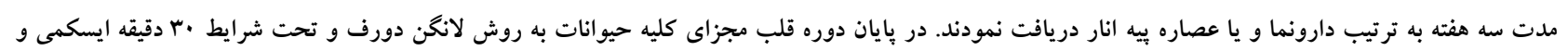

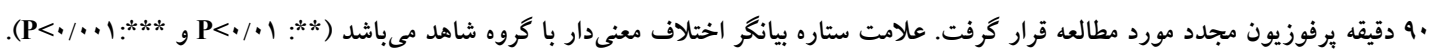


رحيمى و كازرانى

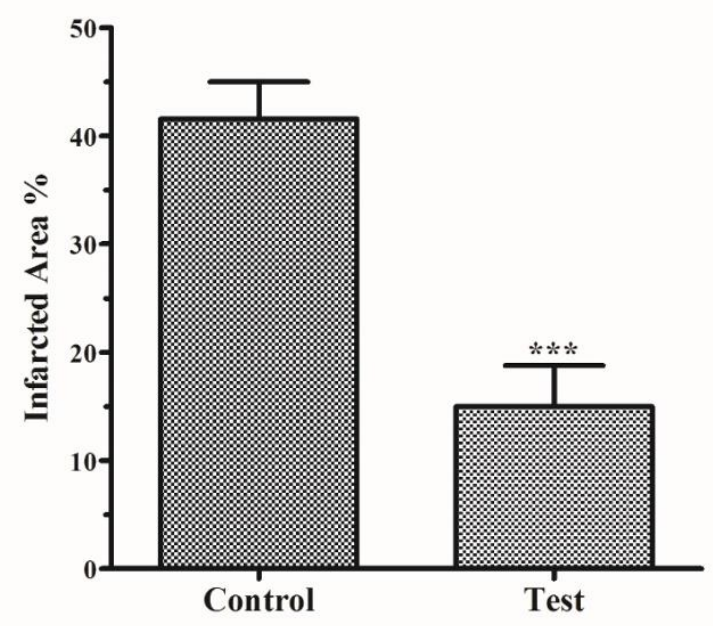

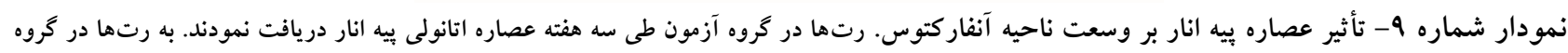

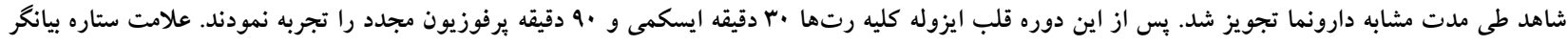

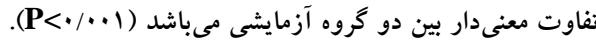

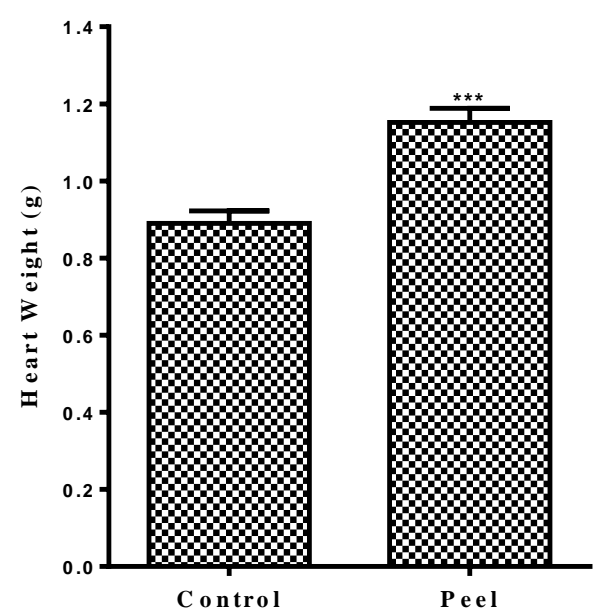

نمودار شماره • ا- تأثير عصاره بيه انار بر وزن قلب در رتهاى مورد آزمايش. طى سه هفته دوره آزمايش، كروههاى شاهد و آزمون به ترتيب دارونما و يا

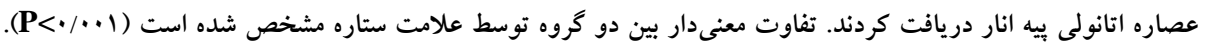

رتهاى گروه آزمون گاواز شد. يّ از اين دوره، قلب تحت

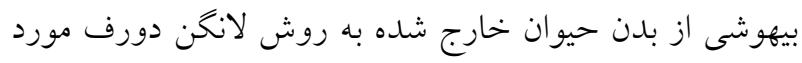
اين يزوهش طى دو مرحله به بررسى تأثير عصاره اتانولى لئ

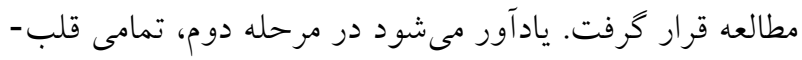

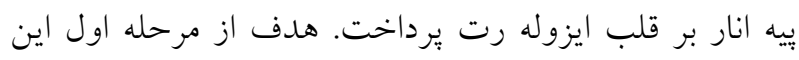

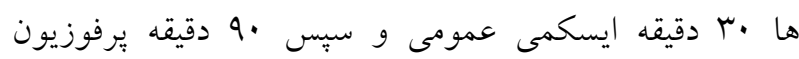

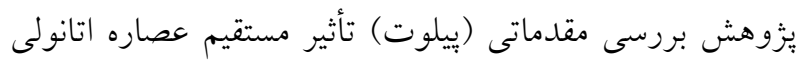
مجدد را تجربه نمودند.

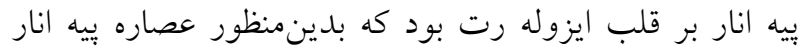

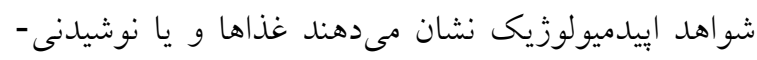

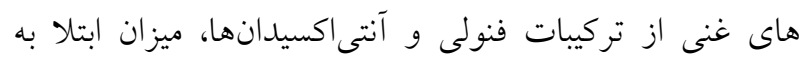

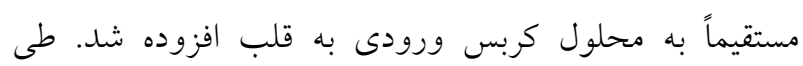

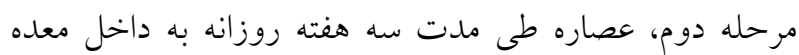


عملكردى دوره يرفوزيون مجدد شامل ديرسيون انقباض،

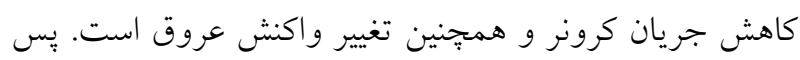

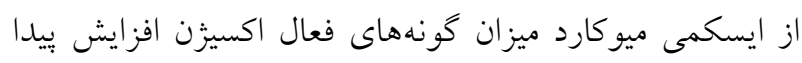

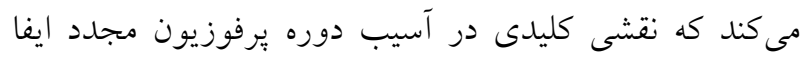

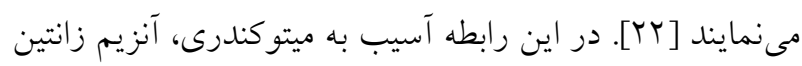

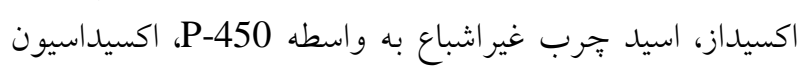

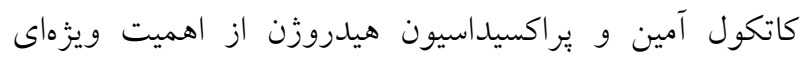

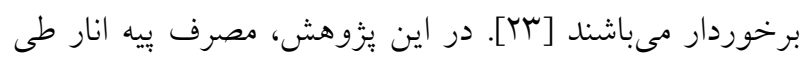

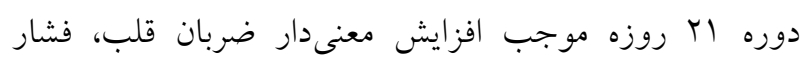

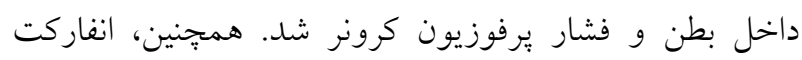

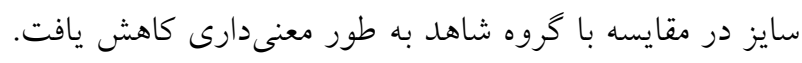

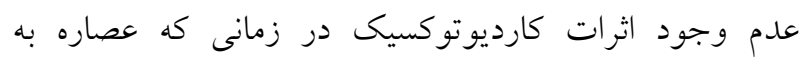

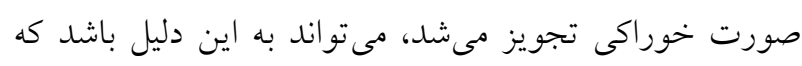

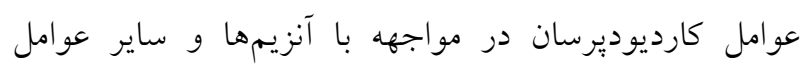

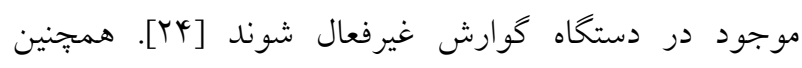

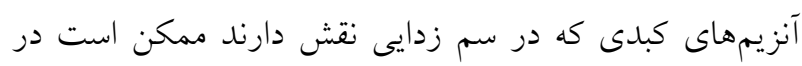

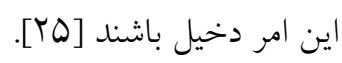

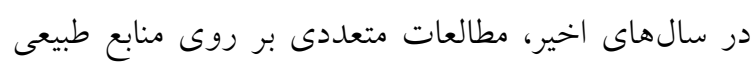

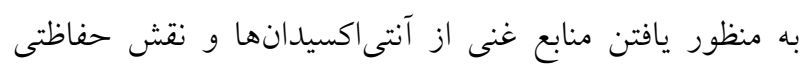

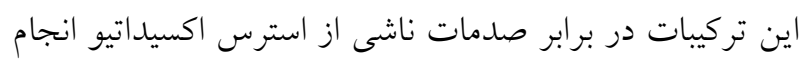
شده است. آنتى اكسيدانهاى مختلفى در اين زمينه مورد استفاده

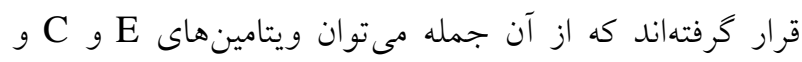

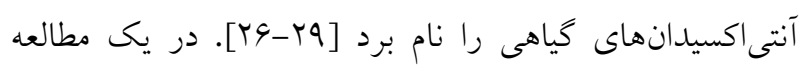

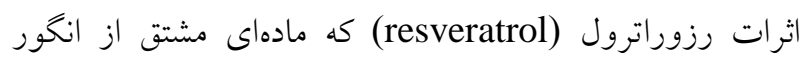

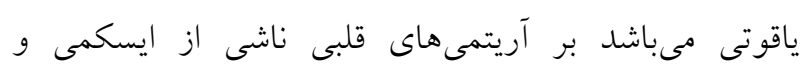

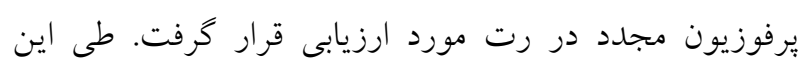

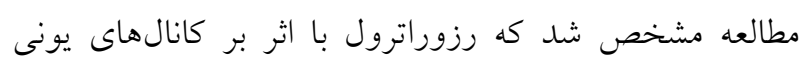

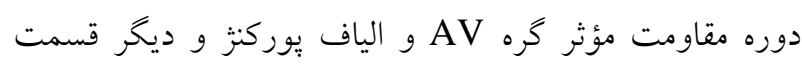

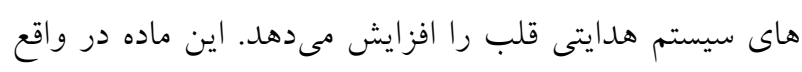

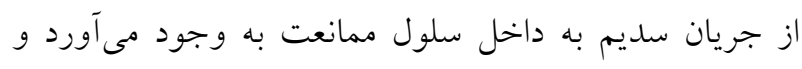

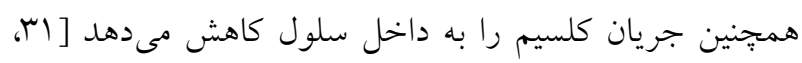

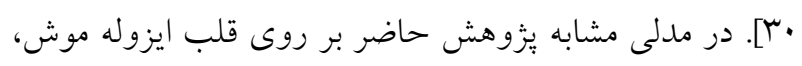

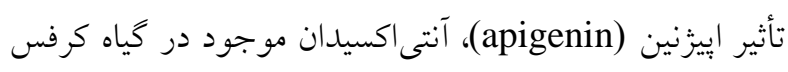

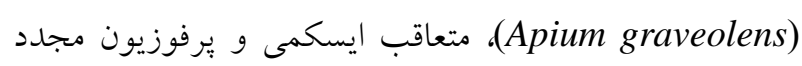

بسيارى از بيمارىها و از جمله بيمارىهاى قلبى - عروقى را

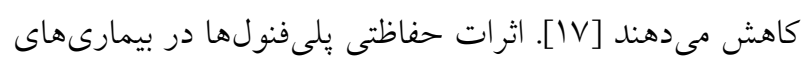

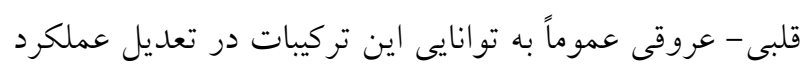

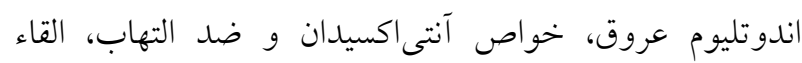
توليد نيتريك اكسيد و انبساط عروق، مهار بيش فعالى بهلاكتها

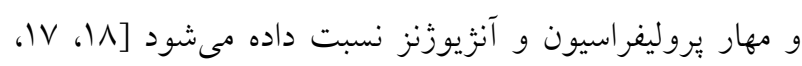

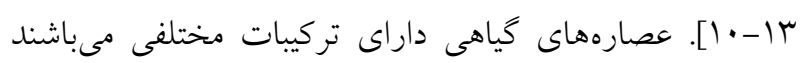

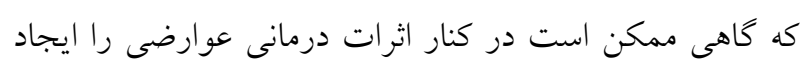

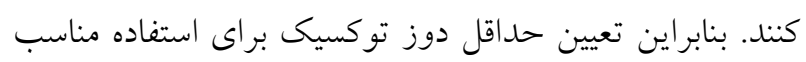

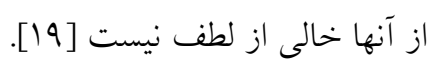
مرحله اول اين مطالعه با هدف امكان افزودن عصاره ييه

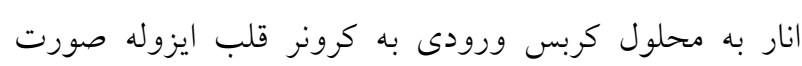

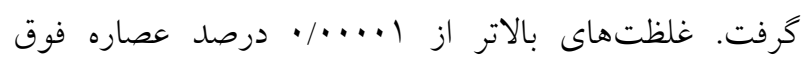

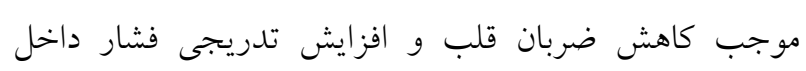

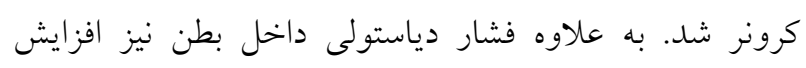

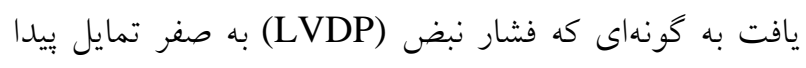

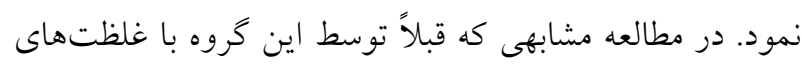

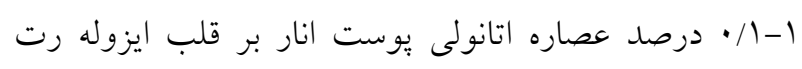

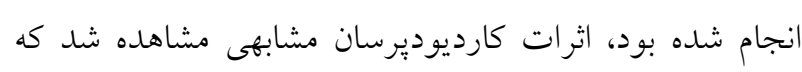

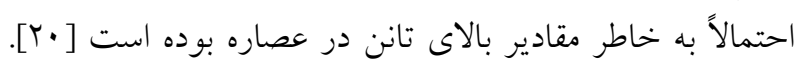

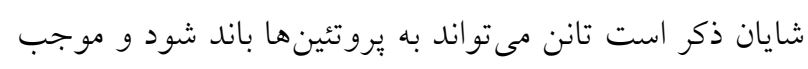

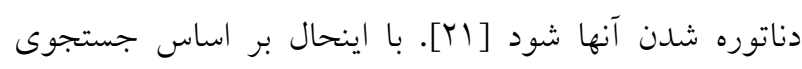

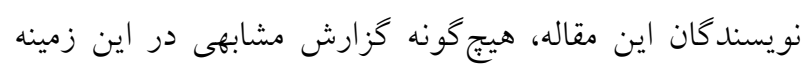

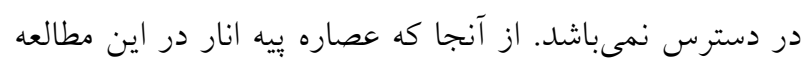
حتى در غلظتهاى بسيار بايين عملكرد طبيعى قلب را مختل دئل

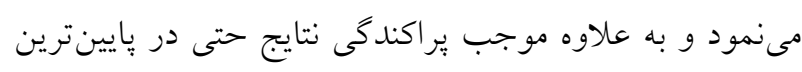

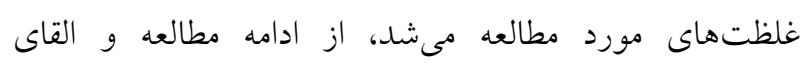

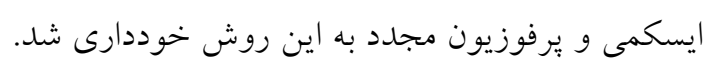

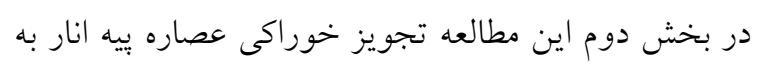

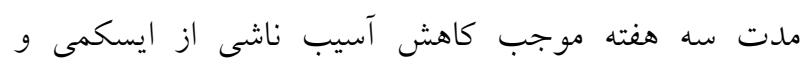
يرفوزيون مجدد در قلب مجزاى حيوان شد. در بيماران مبتلا

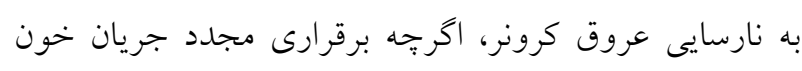

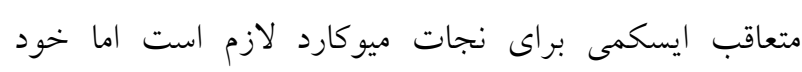

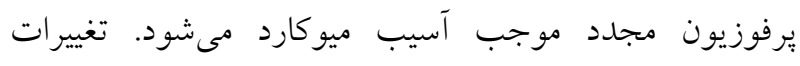




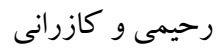

يكسرى تغييرات ساختارى و /يا عملكردى در قلب شده كه به

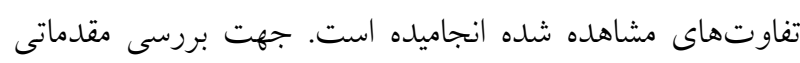

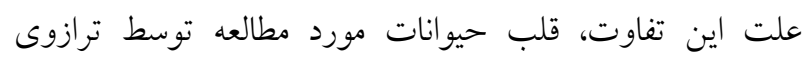
ديجيتال دقيق، توزين شد. جالب آن كه وزن قلب حيوانات گروه آزمون به طور معنى دارى از گروه شاهد بيشتر بود. اين امر بيشنهاد

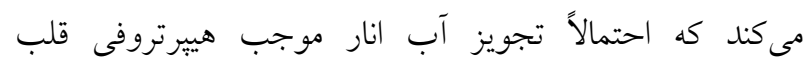

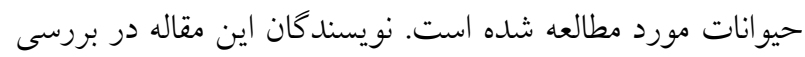

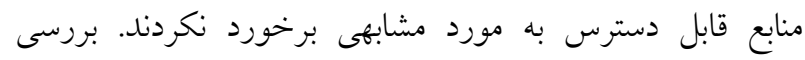

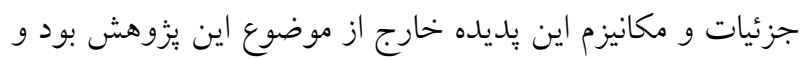

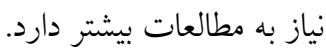

\section{نتيجه كيرى}

نتايج اين يزوهش نشان داد كه يرفوزيون مستقيم قلب

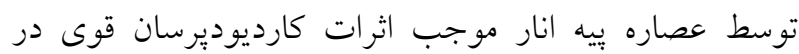
قلب مىشود. اين در حالى است كه يِيش درمانى از طريق

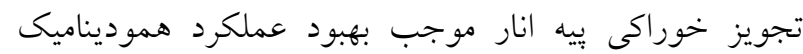

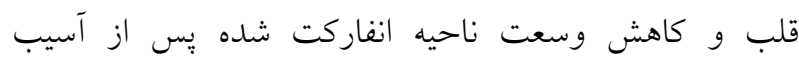
ايسكميك و برفوزيون مجدد ميوكارد مىشود.

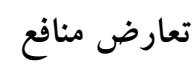

هيج گونه تعارض منافع توسط نويسندگان بيان نشده است.

\section{تشكر و قدردانى}

بدينوسيله از معاونت يزوهشى دانشخاه فردوسى جهت حمايت مالى از اين يزوهش قدردانى مىشود (يزّوهه شماره

.$(Y / 4 \wedge 9 V Y$
ميو كارد بررسى شد. هم راستا با نتايج يزوهش حاضر، إيزئنين

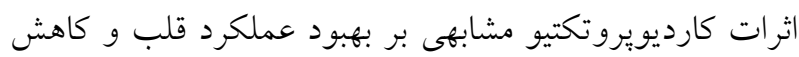
ناحيه انفاركت شده نشان داد [بr]. مطالعه مشابهى با يكى آنتى اكسيدان كياهى تحت عنوان ويتايرو نيز نتايج مشابهى به همراه

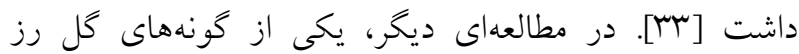
كه داراى خاصيت آنتى اكسيدانى (Xinjiang rosa rugosa) بالايى مىباشد، موجب كاهش انفاركت سايز متعاقب آسيب

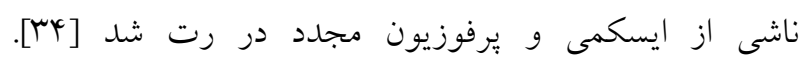

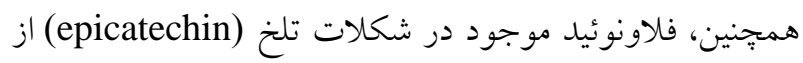
طريق تحريك گيرنده اويوئيدى دلتا، موجب بروز اثرات كارديويروتكتيو شده است [مه]. آب انار حاوى مقادير بالايى

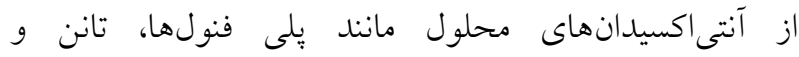
آنتوسيانينها مىباشد. در يكى مطالعه ظرفيت آنتى اكسيدانى و وناني

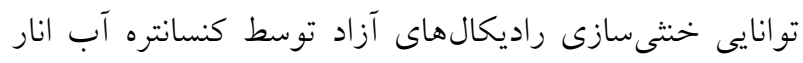

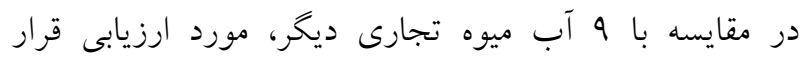
كرفت. بر اساس يافتهاى اين مطالعه، بيشترين ميزان تركيبات

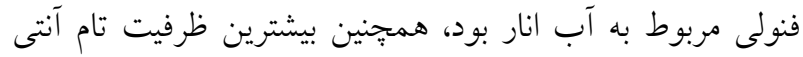

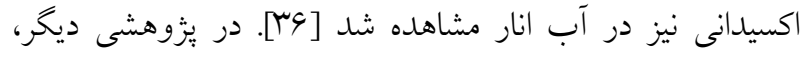

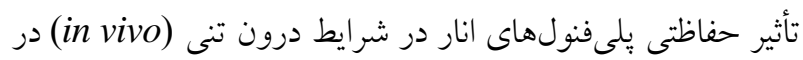

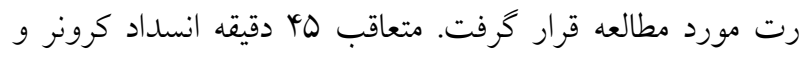

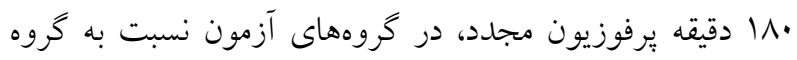
شاهد فعاليت انقباضى قلب به طور معنى دارى بهتر بود و همجينين شاخصهاى آسيب ميوكارد شامل آنزيمهاى كراتين كيناز و لاكتات دهيدروزناز و همجينين وسعت ناحيه انفاركت شده بهبود قابل ملاحظهاى نشان مىداد [TV]].

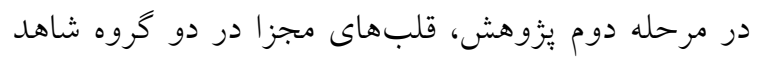

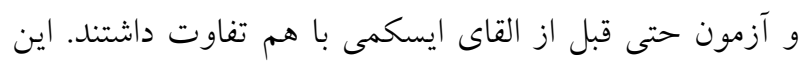

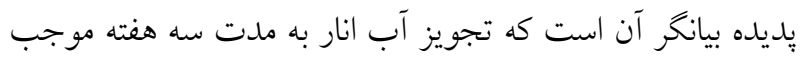

1. Salie R, Huisamen B and Lochner A. High carbohydrate and high fat diets protect the heart against ischaemia/reperfusion injury. Cardiovasc Diabetol. 2014; 18 (13): 109-113.
2. Paradies G, Petrosillo G, Pistolese M, Di Venosa N, Serena D and Ruggiero FM. Lipid peroxidation and alterations to oxidative metabolism in mitochondria isolated from rat heart 
subjected to ischemia and reperfusion. Free Radic. Biol. Med. 1999; 27 (1-2): 42-50.

3. Marín-García $\mathrm{J}$ and Goldenthal MJ. Understanding the impact of mitochondrial defects in cardiovascular disease: a review. J. Card. Fail. 2002; 8 (5): 347-361.

4. Marín-García $J$ and Goldenthal MJ. Heart mitochondria signaling pathways: appraisal of an emerging field. J. Mol. Med. (Berl). 2004; 82 (9): 565-578.

5. Cargnoni A, Ceconi $C$, Bernocchi $P$, Parrinello G, Benigno M, Boraso A, Curello S and Ferrari R. Changes in oxidative stress and cellular redox potential during myocardial storage for transplantation: experimental studies. J. Heart Lung Transplant. 1999; 18 (5): 478-487.

6. Shahzad T, Kasseckert SA, Iraqi W, Johnson V, Schulz R, Schlüter KD, Dörr O, Parahuleva M, Hamm C, Ladilov Y and Abdallah Y. Mechanisms involved in postconditioning protection of cardiomyocytes against acute reperfusion injury. $J$. Mol. Cell Cardiol. 2013; 58 (21): 209-216.

7. Chan PH. Reactive Oxygen Radicals in Signaling and Damage in the Ischemic Brain. $J$. Cereb. Blood Flow Metab. 2001; 21 (1): 2-14.

8. Kini AS, Lee P, Marmur JD, Agarwal A, Duffy ME, Kim MC and Sharma SK. Correlation of postpercutaneous coronary intervention creatine kinase-MB and troponin I elevation in predicting mid-term mortality. Am. J. Cardiol. 2004; 93 (1): 18-23.

9. Levitsky S. Protecting the myocardial cell during coronary revascularization. The William W. L. Glenn Lecture. Circulation. 2006; 114 (1): 339343.

10. Vita JA. Polyphenols and cardiovascular disease: effects on endothelial and platelet function. Am. J. Clin. Nutr. 2005; 81 (1): 292S297S.
11. Ross SM. Pomegranate: Its Role in Cardiovascular Health. Int. J. Nurs. Pract. 2009; 23 (3): 195-7.

12. Yu J, Wang L, Walzem RL, Miller EG, Pike LM and Patil BS. Antioxidant activity of citrus limonoids, flavonoids, and coumarins. J. Agric. Food Chem. 2005; 53 (6): 2009-2014.

13. Malviya S, Arvind, Jha A and Hettiarachchy N. Antioxidant and antibacterial potential of pomegranate peel extracts. J. Food Sci. Technol. 2014; 51 (12): 4132-4137.

14. Al-Megrin W. A. In vivo study of pomegranate (Punica granatum) peel extract efficacy against Giardia lamblia in infected experimental mice. Asian Pac. J. Trop. Biomed. 2017; 7 (1): 59-63.

15. Li Y, Ye T, Yang F, Hu M, Liang L, He H, Li Z, Zeng A, Li Y, Yao Y and Xie Y. Punica granatum (pomegranate) peel extract exerts potent antitumor and anti-metastasis activity in thyroid cancer. RSC Advances. 2016; 87 (6): 84523-84535.

16. Noorbakhsh MF, Arab HA and Kazerani HR. Liver ischemia preconditions the heart against ischemia-reperfusion arrhythmias. IJBMS. 2015; 18 (9): 80-88.

17. Miwa K, Igawa A, Nakagawa K, Hirai $T$ and Inoue $\mathrm{H}$. Consumption of vitamin $\mathrm{E}$ in coronary circulation in patients with variant angina. Cardiovasc. Res. 1999; 8 (3): 291-298.

18. Stoclet JC, Chataigneau T, Ndiaye $M$, Oak MH, El Bedoui J, Chataigneau M and Schini-Kerth VB. Vascular protection by dietary polyphenols. Eur. J. Pharmacol. 2004; 500 (1-3): 299-313.

19. Asif M. A brief study of toxic effects of some medicinal herbs on kidney. Adv. Biomed. Res. 2012; 1 (3): 40-44.

20. Latifipour N KHR. Cardiovascular effects of peel extract on the Isolated Heart of the Rat. AJMP. 2011; 2 (46): 113-120.

21. Tikoo K, Sane MS and Gupta C. Tannic acid 


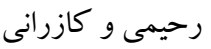

ameliorates doxorubicin-induced cardiotoxicity and potentiates its anti-cancer activity: potential role of tannins in cancer chemotherapy. Toxicol. Appl. Pharmacol. 2011; 251 (3): 191-200.

22. Zweier JL and Talukder MAH. The role of oxidants and free radicals in reperfusion injury. Cardiovasc. Res. 2006; 70 (2): 181-190.

23. Bolli R. Oxygen-derived free radicals and postischemic myocardial dysfunction. JACC. 1988; 12 (1): 239-249.

24. George CF. Drug metabolism by the gastrointestinal mucosa. J. Clin. Pharmacol. 1981; 6 (4): 259-274.

25. Badenhorst $\mathrm{CP}$, van der Sluis R, Erasmus $\mathrm{E}$ and van Dijk AA. Glycine conjugation: importance in metabolism, the role of glycine $\mathrm{N}$ acyltransferase, and factors that influence interindividual variation. Expert Opin. Drug Metab. Toxicol. 2013; 9 (9): 1139-1153.

26. Leifert WR, Jahangiri A and McMurchie EJ. Antiarrhythmic fatty acids and antioxidants in animal and cell studies. J. Nutr. Biochem. 1999; 10 (5): 252-567.

27. Nikas DN, Chatziathanasiou G, Kotsia A, Papamichael N, Thomas C, Papafaklis M, Naka KK, Kazakos N, Milionis HJ, Vakalis K, Katsouras CS, Mpoumpa V, Vougiouklakis T and Michalis L. Effect of intravenous administration of antioxidants alone and in combination on myocardial reperfusion injury in an experimental pig model. Curr. Ther. Res. Clin. Exp. 2008; 69 (5): 423-439.

28. Rice-Evans CA and Diplock AT. Current status of antioxidant therapy. Free Radic. Biol. Med. 1993; 15 (1): 77-96.

29. Laskowski H, Minczykowski A and Wysocki H. Mortality and clinical course of patients with acute myocardial infarction treated with streptokinase and antioxidants: mannitol and ascorbic acid. Int. J. Cardiol. 1995; 48 (3): 235237.

30. Chen W-P, Su M-J and Hung L-M. In vitro electrophysiological mechanisms for antiarrhythmic efficacy of resveratrol, a red wine antioxidant. Eur. J. Pharmacol. 2007; 554 (2-3): 196-204.

31. Singh RB, Niaz MA, Rastogi SS and Rastogi S. Usefulness of antioxidant vitamins in suspected acute myocardial infarction (the Indian experiment of infarct survival-3). Am. J. Cardiol. 2016; 77 (4): 232-236.

32. Hu J, Li Z, Xu LT, Sun AJ, Fu XY, Zhang L, Jing LL, Lu AD, Dong YF and Jia ZP. Protective Effect of Apigenin on Ischemia/Reperfusion Injury of the Isolated Rat Heart. Cardiovasc. Toxicol. 2015; 15 (3): 241-249.

33. Adluri RS, Thirunavukkarasu M, Zhan L, Maulik N, Svennevig K, Bagchi M and Maulik G. Cardioprotective efficacy of a novel antioxidant mix VitaePro against ex vivo myocardial ischemiareperfusion injury. Cell Biochem. Biophys. 2013; 67 (2): 281-286.

34. Hou X, Han J, Yuan C, Ren H, Zhang Y, Zhang $\mathrm{T}, \mathrm{Xu} \mathrm{L}$, Zheng $\mathrm{Q}$ and Chen $\mathrm{W}$. Cardioprotective Effects of Total Flavonoids Extracted from Xinjiang Sprig Rosa rugosa against Acute Ischemia/Reperfusion-Induced Myocardial Injury in Isolated Rat Heart. Cardiovasc. Toxicol. 2016; 16 (1): 54-66.

35. Panneerselvam M, Tsutsumi YM, Bonds JA, Horikawa YT, Saldana M, Dalton ND, Head BP, Patel PM, Roth DM and Patel HH. Dark chocolate receptors: epicatechin-induced cardiac protection is dependent on $\hat{I}^{\prime}$-opioid receptor stimulation. Am. J. Physiol. Heart. Circ. Physiol. 2010; 299 (5): 16041609.

36. Aviram M, Dornfeld L, Kaplan M, Coleman R, Gaitini D, Nitecki S, Hofman A, Rosenblat M,

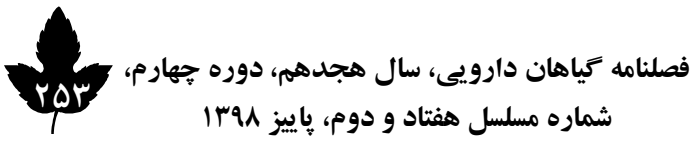




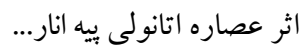

Volkova N, Presser D, Attias J, Hayek T and Fuhrman B. Pomegranate juice consumption reduces oxidative stress, atherogenic modifications to LDL, and platelet aggregation: studies in humans and in atherosclerotic apolipoprotein Edeficient mice. Am. J. Clin. Nutr. 2000; 71 (5): 1062-76.
37. Dong S, Tong X, Liu H and Gao Q. [Protective effects of pomegranate polyphenols on cardiac function in rats with myocardial ischemia/reperfusion injury]. Nan Fang $\mathrm{Yi} \mathrm{Ke} \mathrm{Da}$ Хие Хие Bao. 2012; 32 (7): 924-927. 


\title{
Protective Effect of the Ethanol Extract of Pomegranate Mesocarp on Isolated Rat Heart Following Ischemia and Reperfusion
}

\author{
Rahimi K (Ph.D.) $)^{1}$, Kazerani HR (Ph.D. $)^{2 *}$ \\ 1- Cellular and Molecular Research Center, Research Institute for Health Development, \\ Kurdistan University of Medical Sciences, Sanandaj, Iran \\ 2- Department of Physiology, The School of Veterinary Medicine, Ferdowsi University of \\ Mashhad, Mashhad, Iran \\ *Corresponding author: Department of Physiology, The School of Veterinary Medicine, \\ Mashhad, PO Box: 91775-1793, Iran \\ Tel: +98-51-38805632, Fax: +98-51-38763852 \\ E-mail: kazerani@um.ac.ir, kazrani@yahoo.co.uk
}

\begin{abstract}
Background: Ischemic heart disease is the main cause of mortality worldwide.

Objective: The aim of this study was to investigate the effect of intragastric administration of pomegranate fleshy mesocarp (membrane) extract on isolated rat heart following myocardial ischemia and reperfusion.
\end{abstract}

Methods: Wistar rat's hearts were removed under deep anesthesia and were studied using Langendorff's apparatus. During the first stage of the study, isolated hearts in groups of 3 received different concentrations $(\mathbf{0 . 5 - 0 . 0 0 0 0 1 \% )}$ ) of the extract dissolved in Krebs solution. The control group received pure Krebs solution. During the second stage of the study, the control and the test rats, in groups of 10 , received distilled water or the ethanol extract of pomegranate juice $(200 \mathrm{mg} / \mathrm{kg})$, respectively, daily for 3 weeks. At the end of the experimental period, the hearts of the animals were studied. After 30 min stabilization, all hearts experienced 30 min global ischemia followed by $120 \mathrm{~min}$ reperfusion.

Results: Supplementation of pomegranate membrane extract to perfusion solution of isolated hearts suppressed cardiac mechanical activity and increased coronary perfusion pressure. Intragastric administration of the extract caused a significant increase in heart rate and ventricular contractile force. In addition, coronary perfusion pressure increased, and the infarct size significantly decreased compared to the control group.

Conclusion: Direct administration of the extract to isolated hearts results in cardiac depression. However, intragastric administration of the extract causes strong cardioprotective effects against ischemia and reperfusion induced injury in isolated rat hearts.

Keywords: Ischemia and reperfusion, Isolated heart, Pomegranate mesocarp

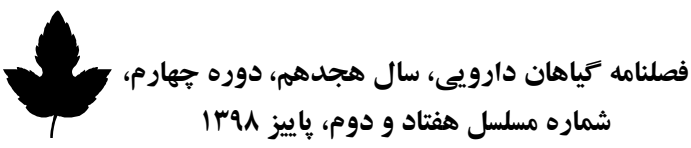

